\title{
Direct Measurement of
}

\section{Photoacoustic Signal Sensitivity to Aerosol Particle Size}

\section{Journal Article}

\section{Author(s):}

Cremer, Johannes (i); Covert, Paul A.; Parmentier, Evelyne A.; Signorell, Ruth (1)

Publication date:

2017-07-20

\section{Permanent link:}

https://doi.org/10.3929/ethz-b-000190398

Rights / license:

In Copyright - Non-Commercial Use Permitted

Originally published in:

The Journal of Physical Chemistry Letters 8(14), https://doi.org/10.1021/acs.jpclett.7b01288 


\section{Direct Measurement of Photoacoustic Signal Sensitivity to Aerosol Particle Size}

Johannes W. Cremer, Paul A. Covert, Evelyne A. Parmentier, and Ruth Signorell* Department of Chemistry and Applied Biosciences, Laboratory of Physical Chemistry, ETH Zürich, Vladimir-Prelog-Weg 2, CH-8093 Zürich, Switzerland

E-mail: rsignorell@ethz.ch 


\begin{abstract}
Continuing efforts to quantify the influence of aerosol light absorption upon global heat budgets rely on high quality measurements of aerosol optical properties. Of the available methods, photoacoustic spectroscopy stands out as a sensitive method for measurements of aerosol absorption with minimal sample modification. Theoretical treatments of photoacoustic aerosol detection have predicted size-dependent damping of the photoacoustic signal as a result of particle thermal inertia. We provide experimental confirmation of this prediction using a single-particle photoacoustic spectrometer, which allows us to measure photoacoustic signals with high sensitivity and size-specificity. Both the magnitude and phase of the photoacoustic response follow the linearized description of the heat flux. The quantification of this effect provides a basis for future, system specific case studies.
\end{abstract}

\title{
Graphical TOC Entry
}

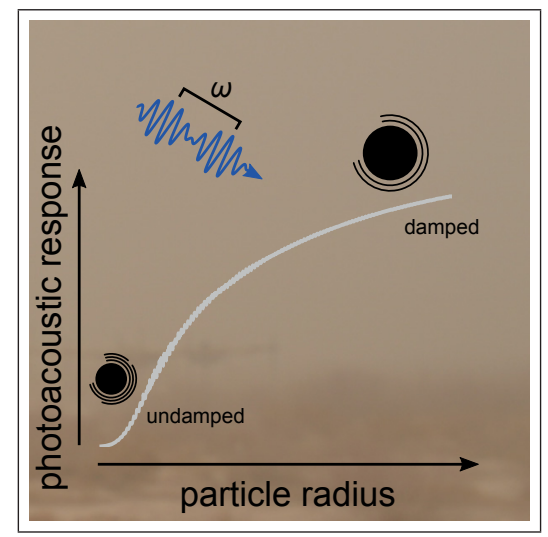

\section{Keywords}

single-particle, optical trapping, aerosol absorption 
Particles aloft in the atmosphere are exposed daily to broad-spectrum, solar radiation. Some fraction of this radiation interacts with the aerosol phase via absorption and scattering processes. It is well established that these interactions affect the Earth's radiative forcing, yet the uncertainty in the magnitude of this forcing remains large; current estimates of climate forcing due to black carbon are $+1.1 \mathrm{~W} \mathrm{~m}^{-2}$ with an uncertainty range of +0.17 to $+2.1 \mathrm{~W} \mathrm{~m}^{-2}{ }^{1,2}$ Despite decades-old awareness of the complexity of the aerosol phase and measurements thereof, ${ }^{3-5}$ the crux remains that it is experimentally challenging to obtain accurate and precise measurements of aerosol optical properties.

Aerosol absorption may be determined indirectly from combined extinction and scattering measurements (extinction minus scattering), directly using filter-based instruments such as the aethelometer ${ }^{6,7}$ and particle soot absorption photometer, ${ }^{8}$ and directly using a flowthrough photoacoustic (PA) spectrometer. ${ }^{9}$ Filter-based methods have found widespread use for the measurement of soot absorption, but uncertainties are typically on the order of 20\%-30\%. ${ }^{2}$ Here, the major source of uncertainty is a bias introduced by light scattering from particles and the filter substrate. To a lesser extent, morphological transformation during particle impaction upon the filter may also bias the absorption measurement. As such, filter-based methods are most effective for the measurement of small size-fraction aerosols with a low single-scattering albedo (SSA); for larger particles and for particles with high SSA, assumptions must be made regarding aerosol properties and loading in order to apply appropriate correction factors. ${ }^{6,10-15}$ Photoacoustic methods, in contrast, are not affected by light scattering and, since they typically operate in flow-through mode, minimize morphological alteration of the aerosol. As a result, photoacoustic spectroscopy is better suited for the measurement of the absorptive properties of aerosols possessing broader size ranges and scattering properties, for example mineral dust ${ }^{11,16}$ and biogenic aerosols. ${ }^{17,18}$ Photoacoustic spectroscopy is not without its own set of challenges, though. High-accuracy, quantitative measurements are still limited by a detailed understanding of the biases in the photoacoustic signal for larger particles and at high relative humidity $(\mathrm{RH})$. The goal of the work presented 
(a)

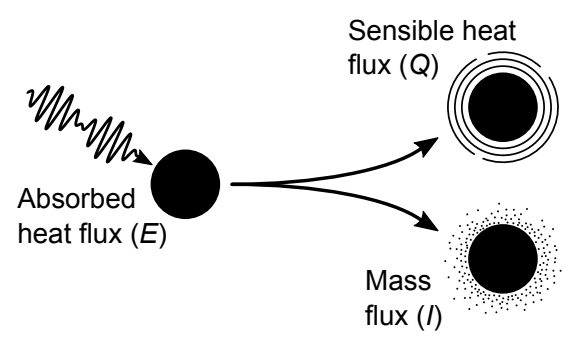

(b)

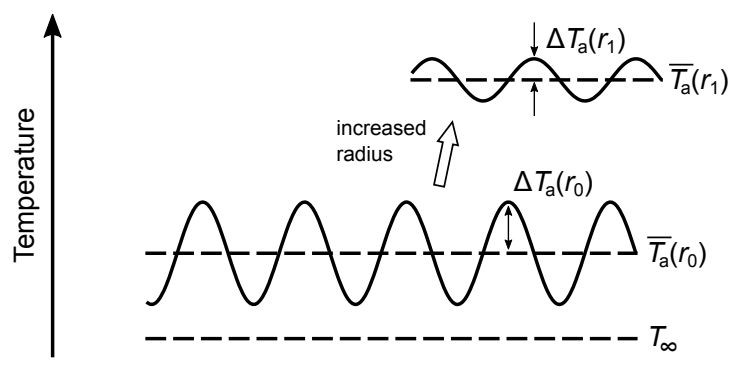

Figure 1: (a) Light energy absorbed by a particle may be dissipated via two pathways during the photoacoustic process. (b) Qualitative illustration of the effect of increasing particle radius $\left(r_{1}>r_{0}\right)$ upon the mean particle temperature, $\bar{T}_{\mathrm{a}}$, and the amplitude of temperature oscillation, $\Delta T_{\mathrm{a}}$, with respect to ambient temperature, $T_{\infty}$.

here is to improve the fundamental understanding of the physics behind the photoacoustic detection process. To this end, we focus on the size-dependence of the photoacoustic (PA) process of single, size-selected aerosol particles. ${ }^{19}$

The photoacoustic effect refers to the conversion of modulated light energy into acoustic energy through a rapid material heating and cooling. ${ }^{20}$ Photoacoustic spectroscopy harnesses this effect and has been developed into a highly sensitive method for detection of trace-level chemical concentrations. Development of photoacoustic spectrometers for the measurement of aerosol absorption ${ }^{9,21-28}$ has progressed hand-in-hand with advances in an understanding of the physical processes underlying the technique (Figure 1). ${ }^{29-31}$ The photoacoustic response from sub-micron sized particles has been observed to be linear with aerosol loading and may be well calibrated. ${ }^{21,32}$ It has been observed, however, that a low bias exists for aerosols at high RH. ${ }^{31,33-35}$ Theoretical treatments of droplet photoacoustics have been developed to account for the observed low bias. ${ }^{29,30,33,36}$ These models also suggest a droplet size-dependence of the photoacoustic response, stemming from the size-dependence of the 
particle's thermal inertia. So far, these predictions have escaped quantitative experimental confirmation, leaving unclear whether the underlying physical descriptions by the models were appropriate. The significance of a reliable understanding of the PA response extends beyond aerosol detection, as it is relevant to condensed phase photoacoustics in general (including e.g. bioanalytics)

The size-dependence of the PA response was investigated using our newly-developed, single-particle photoacoustic spectrometer (SP-PAS) ${ }^{19}$ in which the PA response from single, attoliter volume, optically-trapped particles can be measured. Single particle studies possess the distinct advantage of being able to unambiguously measure size-dependent properties and behavior, bypassing challenges associated with ensemble measurements. ${ }^{19,37-40}$ Due to its single particle nature, the SP-PAS provides a size specificity that is unique among photoacoustic aerosol spectrometers, and as such is an ideal tool for studies of the physics underlying photoacoustic phenomena in aerosols.

Results from two types of experiments are presented (see also Figures S1-S4). In the first experiment, the photoacoustic response was recorded for a series of optically-trapped, single droplets of tetraethylene glycol (TEG) surrounded by pure nitrogen gas. These droplets contained a small amount ( $10 \mathrm{fg}-3 \mathrm{pg})$ of a photoactive solute (Vis441 dye), whose peak absorbance occurs at $441 \mathrm{~nm}$. Angle-dependent elastic light scattering was used for droplet sizing (Figure S2). The photoacoustic excitation source was a $445 \mathrm{~nm}$-wavelength laser, modulated at $4000 \mathrm{~Hz}$. Since the TEG solvent does not absorb at this wavelength, droplet light absorption was due entirely to light absorption by Vis441. The response as a function of particle size is shown by the black dots in Figure 2a. These results are at odds with what might be expected if the photoacoustic signal were purely proportional to the droplet's absorption cross-section, $C_{\text {abs }}$ (calculated by Mie theory with a solution refractive index of $1.463+i 0.0062$; gray line; Figure 2a). While one might argue that the photoacoustic response from small droplets $\left(<1 \mu \mathrm{m}\right.$ radius) can be predicted by assuming proportionality to $C_{\mathrm{abs}}$, the experimental photoacoustic response from large droplets clearly exhibits a size-dependent 

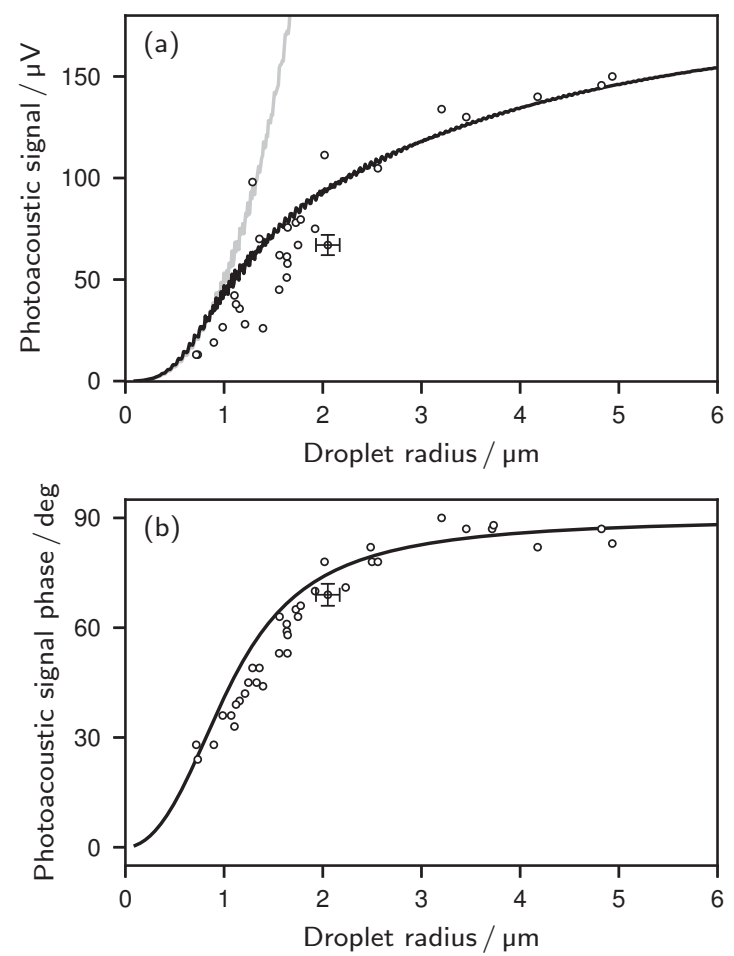

Figure 2: Experimental (open circles) and calculated (black lines) response of the initial amplitude (a) and phase (b) of the photoacoustic signal from multiple, singly-trapped Vis441/TEG droplets after photoexcitation by a laser in the visible range. To facilitate comparison between calculated and experimental responses, the calculated response in (a) was scaled to match the measured signal from large particles. For comparison, a hypothetical

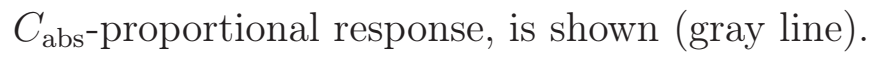

damping compared with the $C_{\text {abs-proportional response. }}$

We next examine our results in the context of previously-suggested photoacoustic models of aerosols. ${ }^{30,33}$ Since the particle PA responses shown in Figure 2 originate from particles of radius $\geq 0.7 \mu \mathrm{m}$, we assume that our system is adequately described by continuum flow mechanics. Therefore, we have omitted the transition flow correction terms originally presented by Murphy. ${ }^{30}$ The photoacoustic response stems from the conversion of absorbed light energy into heat which is dissipated to the surrounding gas, resulting in a volume expansion, $\Delta V$. This expansion may be expressed as a sum of the individual volume expansions (Figure 1a) due to heating, $\Delta V_{Q}$, and evaporation, $\Delta V_{I}$, such that

$$
\Delta V=\Delta V_{Q}+\Delta V_{I}
$$


The sensible heat flux, $Q$, and the mass flux, $I$, away from the particle balance the energy flux, $E$, into the particle due to light absorption

$$
E(t, \omega)=Q\left(r, T_{\mathrm{a}}\right)+I\left(r, x_{\mathrm{a}}\right) \cdot L+m_{\mathrm{a}} c_{p, \mathrm{a}} \frac{\partial T_{\mathrm{a}}}{\partial t}
$$

where $t$ is time, $\omega$ is the modulation frequency of the light, $r$ is the particle radius, $T_{\mathrm{a}}$ is the particle temperature, $x_{\mathrm{a}}$ is the molar concentration of the evaporating species at the particle's surface, $L$ is the latent heat of evaporation, and $c_{p, \mathrm{a}}$ and $m_{\mathrm{a}}$, are the specific heat capacity and mass, respectively, of the particle. For small temperature differences, the heat flux is linearly dependent upon particle radius and temperature,

$$
Q\left(r, T_{\mathrm{a}}\right) \approx 4 \pi r K\left(T_{\mathrm{a}}-T_{\infty}\right)
$$

Here, $K$ is the heat conductivity of the surrounding gas and $T_{\infty}$ is the ambient temperature. Analogously, the mass flux is approximately proportional to the particle size and to the difference in molar concentration of the evaporating species at the surface of the particle, $x_{\mathrm{a}}$, and far from the particle, $x_{\infty}$,

$$
I\left(r, x_{\mathrm{a}}\right) \approx 4 \pi r D M_{\mathrm{v}}\left(x_{\mathrm{a}}-x_{\infty}\right),
$$

where $D$ is the diffusion constant of the evaporating species in air and $M_{\mathrm{v}}$ is the molar mass of the evaporating species. Using the linearized Clausius-Clapeyron equation to express eq 4, eq 2 can be solved analytically. The total PA response, and therefore the measured PA signal, $S$, results from the oscillatory components of $Q\left(r, T_{\mathrm{a}}\right)$ and $I\left(r, x_{\mathrm{a}}\right)$

$$
S \propto \frac{R}{p}\left(\frac{\Delta Q(r)}{M_{\mathrm{g}} c_{p, \mathrm{~g}}}+\frac{\Delta I(r) T_{\infty}}{M_{\mathrm{v}}}\right)
$$

where $M_{\mathrm{g}}$ and $c_{p, \mathrm{~g}}$ denote the molar mass and the heat capacity, respectively, of the sur- 
rounding gas. The oscillatory amplitudes, $\Delta Q(r)$ and $\Delta I(r)$, are related through eq 3 and eq 4 to the amplitude of the temperature oscillation, $\Delta T_{\mathrm{a}}$, which is given by the solution to eq 2 (see model derivation in Supporting Information for more detail).

To apply this theory to the data shown in Figure 2a, a couple of assumptions are made. It is assumed that the energy absorbed by Vis441 is rapidly and uniformly transferred to the TEG solvent and that it is the thermal oscillation of TEG that yields the PA response. Secondly, it is assumed that, due to the low vapor pressure of TEG, evaporation has no significant contribution to $\Delta T_{\mathrm{a}}$ or the photoacoustic response. Figure S5 demonstrates that evaporation is indeed negligible on the timescale of the experiment (minutes). Substitution of thermodynamic constants for TEG and $\mathrm{N}_{2}$ (Table S1) into eqs 3-5 yields a model-predicted response (black line; Figure 2) whose shape matches the response measured from the individual Vis441/TEG droplets. In particular, the signal of the larger particles is well reproduced

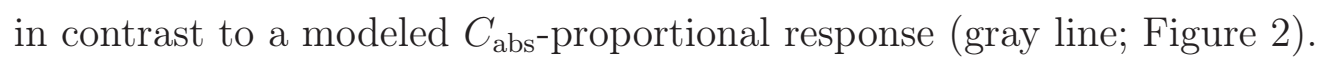

Because the temperature oscillation is ultimately responsible for the photoacoustic signal, it is instructive to investigate how the signal is affected by changes in particle size (Figure 1b). The mean particle temperature, $\bar{T}_{\mathrm{a}}$, during the photoacoustic process is elevated above ambient temperature (eq S13). The amplitude of the oscillation around $\bar{T}_{\mathrm{a}}$ is given by

$$
\Delta T_{\mathrm{a}}=\frac{I_{0} C_{\mathrm{abs}}(r)}{4 \pi r K\left|1+f_{\mathrm{M}}-i \omega \tau(r)\right|},
$$

where $I_{0}$ is the incident light intensity and $I_{0} C_{\mathrm{abs}}(r)=E_{0}$ is the average power absorbed by the particle, $f_{M}=\Delta I \cdot L / \Delta Q$ (which is approximately 0 for the present case) represents the ratio of latent heat flux to sensible heat flux, $\tau=r^{2} \rho_{\mathrm{a}} c_{p, \mathrm{a}} / 3 K$ is the time constant that accounts for the thermal inertia of the particle, and $\rho_{\mathrm{a}}$ is the density of the particle. A particle radius term occurs twice in the denominator of eq 6 , both explicitly and implicitly in $\tau$. It follows that an increase in $r$ serves to increase the damping of the temperature oscillation. To a certain extent, this damping can be counteracted by decreasing the modulation frequency 
of the excitation laser. Likewise an increase in evaporation (i.e. increased $f_{\mathrm{M}}$ ) damps the temperature oscillation.

In addition to affecting $\Delta T_{\mathrm{a}}$, particle size and evaporation may also introduce a phase shift between the modulation phase of the excitation laser and the phase of the temperature oscillation, given by

$$
\varphi\left(T_{\mathrm{a}}\right)=\arg \left[\frac{1}{1+f_{\mathrm{M}}-i \omega \tau(r)}\right] .
$$

An increase in particle radius introduces a phase lag through an increase in $\tau$. Increased evaporation counters this phase lag. In a measurement this manifests itself as a delay between the optical excitation and the photoacoustic response. Comparison of the modeled phase response to our Vis441/TEG data shows a good agreement between the two, with a phase lag of approximately $30^{\circ}$ for small particles, approaching $90^{\circ}$ for large particles (Figure 2b).

The photoacoustic response from the Vis441/TEG droplets (Figure 2) resulted from excitation in the visible spectral range of the Vis441 dye. A similar experiment was performed in which photoacoustic excitation in the far infrared $(\lambda=9.47 \mu \mathrm{m}$, which corresponds to the $\mathrm{C}-\mathrm{O}$ absorption in TEG and a refractive index of $\approx 1.4+i 0.2)$ was used to directly probe absorption in pure TEG droplets. In this experiment, a single TEG droplet was trapped for approximately one hour, during which both the photoacoustic response and the droplet size were continuously monitored. The droplet size was retrieved from the integrated intensity of the light elastically scattered by the droplet (Figure S3). It was observed that both the amplitude of the photoacoustic response (Figure 3) and the overall scattered light intensity (Figure S3a) decreased over the course of the hour. This analysis showed that over time the droplet decreased in size due to a slow evaporation of TEG (Figure S4). The net result is a measure of the photoacoustic response from a TEG droplet as a function of droplet size (circles; Figure 3). As in the case of the Vis441/TEG analysis, the amplitude of the photoacoustic response from TEG increases with increasing droplet size and is damped with respect to a hypothetical response based on $C_{\text {abs }}$ only (gray line; Figure 3a). Use of eq 5 to model the amplitude response from a pure TEG droplet (black line; Figure 3a) agrees 

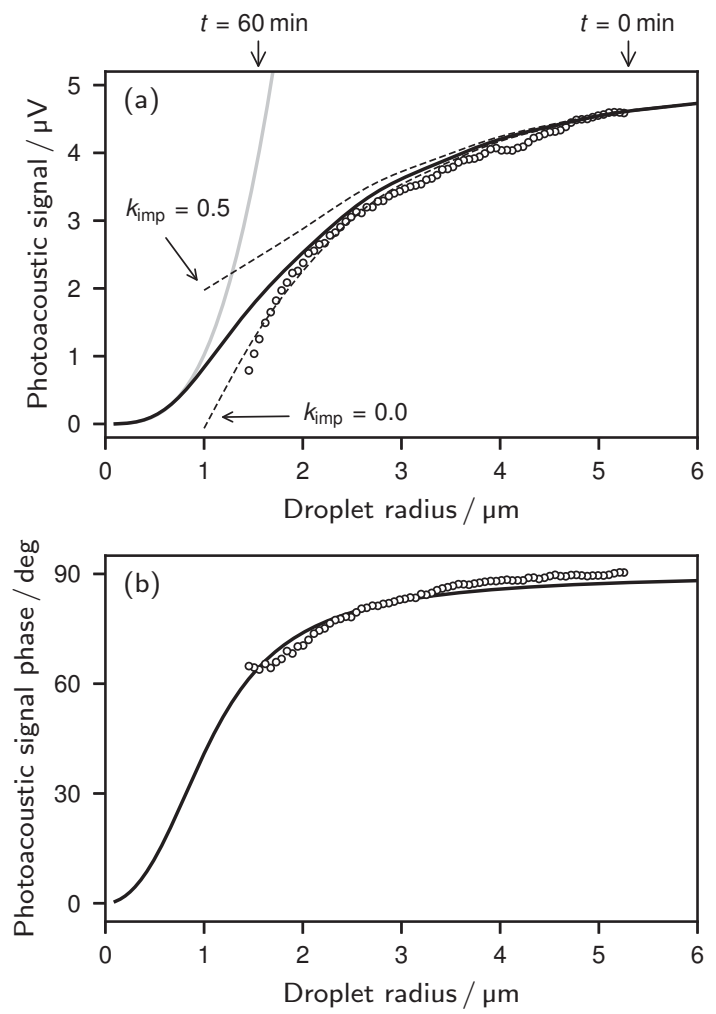

Figure 3: Experimental amplitude (a) and phase (b) of the photoacoustic response measured from a single TEG droplet after photoexcitation by an infrared laser (circles). Modeled photoacoustic responses from a single, pure TEG droplet (solid line) and from TEG droplets containing a small amount ( $0.5 \%$ by volume) of impurity (dashed lines) are shown. For

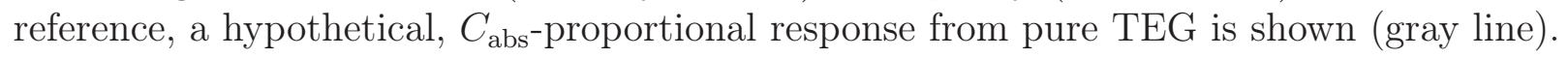

well with the experimental data for larger droplet sizes, but it overestimates the observed amplitude response from droplets smaller than approximately $2 \mu \mathrm{m}$ in radius.

We explain this discrepancy by a small amount of a non-volatile impurity in the droplet, which becomes more concentrated upon droplet shrinking. In our experiment, the droplet radius decreases from approximately $5 \mu \mathrm{m}$ to $<2 \mu \mathrm{m}$, or by $95 \%$ decrease in volume. For TEG the manufacturer quotes an impurity level of $0.5 \%$. For the purposes of our simulations (dashed lines; Figure 3a), we assumed that the impurities have a refractive index of $1.4+i k_{\text {imp }}$ and that they do not evaporate over the course of our experiment. The increase in concentration of the impurity upon droplet shrinking results in a correspondingly size-dependent refractive index of the droplet. The sensitivity of the PA response to both the real and imaginary parts ( $n_{\mathrm{imp}}$ and $k_{\mathrm{imp}}$, respectively) of the impurity refractive index was examined; 
it was found that varying $k_{\mathrm{imp}}$ had the greatest effect upon the photoacoustic signal. The experimental PA signal in Figure $3 \mathrm{a}$ is well reproduced for $k_{\mathrm{imp}}=0$ (corresponding dashed line) which lends support to our hypothesis that the TEG droplet contains a small amount of a non-volatile impurity that is a much weaker absorber than TEG at the wavelength of $9.47 \mu \mathrm{m}$. For completeness, Figure 3a also shows that case of a strongly absorbing impurity $\left(k_{\mathrm{imp}}=0.5\right)$.

In summary, our single-particle photoacoustic setup, with attogram detection sensitivity, has made it possible to study fundamental aspects of the photoacoustic detection process. Our results show that the size dependence of the conductive heat loss contribution to the photoacoustic response is a large effect, which occurs in all types of aerosol particles irrespective of their composition. First predicted decades ago, we find that simple linearized models are sufficient to quantify the thermal inertia effects over a broad particle size range. Particles containing highly volatile components can show additional mass flux contributions to the photoacoustic response. Contrary to the conductive heat loss, mass flux contributions are highly system specific depending on the specific properties of both the particle and the surrounding gas phase. Model calculations indicate that conductive heat loss generally dominates for particles in the micron range (e.g. mineral dust). Our single-particle photoacoustic setup now provides the experimental basis for also quantifying such system specific phenomena.

\section{Experimental Methods}

Radius and photoacoustic signal from single, optically-trapped tetraethylene glycol (ACROS Organics; $99.5 \%$ ) droplets and homogeneously-mixed droplets of a photoactive dye (QCR Solutions; Vis441A) in TEG were measured with an experimental setup slightly modified from the setup described in Cremer et al. ${ }^{19}$ A schematic of the experimental setup is pre- 
sented in the Supporting Information (Figure S1). In brief, an aerosol stream is generated with a nebulizer and is introduced to the optical trap through an inlet port of the photoacoustic cell. A single droplet from this aerosol stream was immobilized by a pair of counter-propagating, optical tweezers and the photoacoustic cell purged with dry nitrogen gas, flowing at $2 \mathrm{~mL} \mathrm{~min}^{-1}$, to remove all untrapped aerosol from the photoacoustic resonance chamber. The immobilized droplet was excited using a $4 \mathrm{kHz}$-modulated laser and the photoacoustic response detected with a microphone mounted on the bottom of the photoacoustic cell. As a photoacoustic excitation source, we used a $445 \mathrm{~nm}$-wavelength laser for the mixed Vis441/TEG droplets and a $9.47 \mu \mathrm{m}$-wavelength laser for the TEG droplets. Prior to photobleaching, the refractive index of the Vis441/TEG droplets at $445 \mathrm{~nm}$ was $1.463+i 0.0062 .{ }^{19}$ Using a Kramers-Kronig transformation of a FTIR spectrum of TEG, we determined the refractive index of TEG at $9.47 \mu \mathrm{m}$ to be $1.4+i 0.2$. A camera mounted above the PA cell recorded the light scattered from the droplet over a $48.2^{\circ}$ viewing angle. The radius of Vis441/TEG particles was determined by fitting a calculated scattering image using Mie theory ${ }^{41}$ to the experimental scattering image (Figure S2). The uncertainty in particle radius was typically $\pm 0.12 \mu \mathrm{m}$. The time-dependent radius of the pure TEG droplet was determined over the course of an hour by monitoring the total scattering intensity, which peaks sharply when the shrinking droplet passes through a Mie resonance (Figure S3). The radius was determined from a fit of calculated intensities to experimental intensities using Mie theory. ${ }^{42}$ In the case of Vis441/TEG droplets, illumination of the droplets with the excitation laser initiates a photobleaching of the Vis441 dye. The initial signal amplitude represents the absorption of the droplet immediately prior to photobleaching, and was determined by fitting the data to a first-order model of the decay, which has been shown to be a good approximation to the actual decay for small particles. ${ }^{19}$ 


\section{Acknowledgement}

We acknowledge funding by the ETH Zürich and the Swiss National Science Foundation (SNSF).

\section{Supporting Information Available}

The Supporting Information is available free of charge on the ACS Publications website at DOI: $10.1021 /$ acs.jpclett.xxxxxx.

The Supporting Information includes a derivation of the photoacoustic response model. Table S1 lists values for the thermophysical constants used to parameterize the model. Supplemental figures (Figures S1-S3) illustrate the experimental setup and methods for sizing trapped particles. Figure S4 shows the gradual shrinking of an single TEG droplet over the course of one hour. Figure S5 presents the sensitivity of the photoacoustic signal to evaporation of TEG.

This material is available free of charge via the Internet at http://pubs.acs.org/.

\section{References}

(1) IPCC, In Climate Change 2013 - The Physical Science Basis. Contribution of Working Group I to the Fifth Assessment Report of the Intergovernmental Panel on Climate Change; Stocker, T. F., Qin, D., Plattner, G.-K., Tignor, M., Allen, S. K., Boschung, J., Nauels, A., Xia, Y., Bex, V., Midgley, P. M., Eds.; Cambridge University Press, 2013; pp 571-658.

(2) Bond, T. C.; Doherty, S. J.; Fahey, D. W.; Forster, P. M.; Berntsen, T.; DeAngelo, B. J.; Flanner, M. G.; Ghan, S.; Kärcher, B.; Koch, D. et al. Bounding the Role of Black Carbon in the Climate System: A Scientific Assessment. J. Geophys. Res. Atmos. 2013, 118, 5380-5552. 
(3) Jacobson, M. Z. Strong Radiative Heating due to the Mixing State of Black Carbon in Atmospheric Aerosols. Nature 2001, 409, 695-697.

(4) Andreae, M. O. The Dark Side of Aerosols. Nature 2001, 409, 671-672.

(5) Moosmüller, H.; Chakrabarty, R.; Arnott, W. Aerosol Light Absorption and its Measurement: A Review. J. Quant. Spectrosc. Radiat. Transfer 2009, 110, 844-878.

(6) Weingartner, E.; Saathoff, H.; Schnaiter, M.; Streit, N.; Bitnar, B.; Baltensperger, U. Absorption of Light by Soot Particles: Determination of the Absorption Coefficient by Means of Aethalometers. J. Aerosol Sci. 2003, 34, 1445-1463.

(7) Hansen, A. D. A. The Aethalometer. Magee Scientific: Berkeley, CA, USA, 2005.

(8) Springston, S. R. Particle Soot Absorption Photometer (PSAP) Instrument Handbook; techreport DOE/SC-ARM-TR-176, 2016.

(9) Arnott, W. P.; Moosmüller, H.; Rogers, C. F.; Jin, T.; Bruch, R. Photoacoustic Spectrometer for Measuring Light Absorption by Aerosol: Instrument Description. Atmos. Environ. 1999, 33, 2845-2852.

(10) Baumgardner, D.; Popovicheva, O.; Allan, J.; Bernardoni, V.; Cao, J.; Cavalli, F.; Cozic, J.; Diapouli, E.; Eleftheriadis, K.; Genberg, P. J. et al. Soot Reference Materials for Instrument Calibration and Intercomparisons: A Workshop Summary with Recommendations. Atmos. Meas. Tech. 2012, 5, 1869-1887.

(11) Moosmüller, H.; Engelbrecht, J. P.; Skiba, M.; Frey, G.; Chakrabarty, R. K.; Arnott, W. P. Single Scattering Albedo of Fine Mineral Dust Aerosols Controlled by Iron Concentration. J. Geophys. Res. 2012, 117.

(12) Johnson, B. T.; Osborne, S. R. Physical and Optical Properties of Mineral Dust Aerosol Measured by Aircraft During the GERBILS Campaign. Quart. J. Roy. Meteor. Soc. 2011, 13\%, 1117-1130. 
(13) Lewis, K.; Arnott, W. P.; Moosmüller, H.; Wold, C. E. Strong Spectral Variation of Biomass Smoke Light Absorption and Single Scattering Albedo Observed with a Novel Dual-Wavelength Photoacoustic Instrument. J. Geophys. Res. 2008, 113.

(14) Bond, T. C.; Anderson, T. L.; Campbell, D. Calibration and Intercomparison of FilterBased Measurements of Visible Light Absorption by Aerosols. Aerosol Sci. Technol. 1999, 30, 582-600.

(15) Virkkula, A.; Ahlquist, N. C.; Covert, D. S.; Arnott, W. P.; Sheridan, P. J.; Quinn, P. K.; Coffman, D. J. Modification, Calibration and a Field Test of an Instrument for Measuring Light Absorption by Particles. Aerosol Sci. Technol. 2005, 39, $68-83$.

(16) Russell, P. B.; Bergstrom, R. W.; Shinozuka, Y.; Clarke, A. D.; DeCarlo, P. F.; Jimenez, J. L.; Livingston, J. M.; Redemann, J.; Dubovik, O.; Strawa, A. Absorption Angstrom Exponent in AERONET and Related Data as an Indicator of Aerosol Composition. Atmos. Chem. Phys. 2010, 10, 1155-1169.

(17) Després, V. R.; Huffman, J. A.; Burrows, S. M.; Hoose, C.; Safatov, A. S.; Buryak, G.; Fröhlich-Nowoisky, J.; Elbert, W.; Andreae, M. O.; Pöschl, U. et al. Primary Biological Aerosol Particles in the Atmosphere: A Review. Tellus B: Chemical and Physical Meteorology 2012, 64, 15598.

(18) Quinn, P. K.; Collins, D. B.; Grassian, V. H.; Prather, K. A.; Bates, T. S. Chemistry and Related Properties of Freshly Emitted Sea Spray Aerosol. Chem. Rev. 2015, 115, $4383-4399$.

(19) Cremer, J. W.; Thaler, K. M.; Haisch, C.; Signorell, R. Photoacoustics of Single LaserTrapped Nanodroplets for the Direct Observation of Nanofocusing in Aerosol Photokinetics. Nat. Commun. 2016, 7, 10941. 
(20) Haisch, C. Photoacoustic Spectroscopy for Analytical Measurements. Meas. Sci. Technol. 2012, 23, 012001.

(21) Lack, D. A.; Lovejoy, E. R.; Baynard, T.; Pettersson, A.; Ravishankara, A. R. Aerosol Absorption Measurement using Photoacoustic Spectroscopy: Sensitivity, Calibration, and Uncertainty Developments. Aerosol Sci. Technol. 2006, 40, 697-708.

(22) Ajtai, T.; Ágnes Filep,; Schnaiter, M.; Linke, C.; Vragel, M.; Bozóki, Z.; Szabó, G.; Leisner, T. A Novel Multi-Wavelength Photoacoustic Spectrometer for the Measurement of the UV-NIR Spectral Absorption Coefficient of Atmospheric Aerosols. J. Aerosol Sci. 2010, 41, 1020-1029.

(23) Bueno, P. A.; Havey, D. K.; Mulholland, G. W.; Hodges, J. T.; Gillis, K. A.; Dickerson, R. R.; Zachariah, M. R. Photoacoustic Measurements of Amplification of the Absorption Cross Section for Coated Soot Aerosols. Aerosol Sci. Technol. 2011, 45, $1217-12230$.

(24) Haisch, C.; Menzenbach, P.; Bladt, H.; Niessner, R. A Wide Spectral Range Photoacoustic Aerosol Absorption Spectrometer. Anal. Chem. 2012, 84, 8941-8945.

(25) Sharma, N.; Arnold, I. J.; Moosmüller, H.; Arnott, W. P.; Mazzoleni, C. Photoacoustic and Nephelometric Spectroscopy of Aerosol Optical Properties with a Supercontinuum Light Source. Atmos. Meas. Tech. 2013, 6, 3501-3513.

(26) Wiegand, J. R.; Mathews, L. D.; Smith, G. D. A UV-Vis Photoacoustic Spectrophotometer. Anal. Chem. 2014, 86, 6049-6056.

(27) Radney, J. G.; Zangmeister, C. D. Measurement of Gas and Aerosol Phase Absorption Spectra across the Visible and Near-IR Using Supercontinuum Photoacoustic Spectroscopy. Anal. Chem. 2015, 87, 7356-7363. 
(28) Langridge, J. M.; Richardson, M. S.; Lack, D. A.; Murphy, D. M. Experimental Evidence Supporting the Insensitivity of Cloud Droplet Formation to the Mass Accommodation Coefficient for Condensation of Water Vapor to Liquid Water. Geophys. Res. Lett. 2016, 43, 6650-6656.

(29) Raspet, R.; Slaton, W. V.; Arnott, W. P.; Moosmüller, H. Evaporation-Condensation Effects on Resonant Photoacoustics of Volatile Aerosols. J. Atmos. Oceanic Technol. 2003, 20, 685-695.

(30) Murphy, D. M. The Effect of Water Evaporation on Photoacoustic Signals in Transition and Molecular Flow. Aerosol Sci. Technol. 2009, 43, 356-363.

(31) Langridge, J. M.; Richardson, M. S.; Lack, D. A.; Brock, C. A.; Murphy, D. M. Limitations of the Photoacoustic Technique for Aerosol Absorption Measurement at High Relative Humidity. Aerosol Sci. Technol. 2013, 47, 1163-1173.

(32) Beck, H. A.; Niessner, R.; Haisch, C. Development and Characterization of a Mobile Photoacoustic Sensor for On-line Soot Emission Monitoring in Diesel Exhaust Gas. Anal. Bioanal.Chem. 2003, 375, 1136-1143.

(33) Arnott, W. P.; Moosmüller, H.; Sheridan, P. J.; Ogren, J. A.; Raspet, R.; Slaton, W. V.; Hand, J. L.; Kreidenweis, S. M.; Collett, J. L. Photoacoustic and Filter-Based Ambient Aerosol Light Absorption Measurements: Instrument Comparisons and the Role of Relative Humidity. J. Geophys. Res. Atmos. 2003, 108, AAC 15-1-15-11.

(34) Lewis, K. A.; Arnott, W. P.; Moosmüller, H.; Chakrabarty, R. K.; Carrico, C. M.; Kreidenweis, S. M.; Day, D. E.; Malm, W. C.; Laskin, A.; Jimenez, J. L. et al. Reduction in Biomass Burning Aerosol Light Absorption Upon Humidification: Roles of Inorganically-Induced Hygroscopicity, Particle Collapse, and Photoacoustic Heat and Mass Transfer. Atmos. Chem. Phys. 2009, 9, 8949-8966. 
(35) Lack, D. A.; Quinn, P. K.; Massoli, P.; Bates, T. S.; Coffman, D.; Covert, D. S.; Sierau, B.; Tucker, S.; Baynard, T.; Lovejoy, E. et al. Relative Humidity Dependence of Light Absorption by Mineral Dust after Long-Range Atmospheric Transport from the Sahara. Geophys. Res. Lett. 2009, 36, L24805.

(36) Baker, M. Energy Absorption by Volatile Atmospheric Aerosol Particles. Atmos. Environ. 1976, 10, 241-248.

(37) Krieger, U. K.; Marcolli, C.; Reid, J. P. Exploring the Complexity of Aerosol Particle Properties and Processes Using Single Particle Techniques. Chemical Society Reviews 2012, 41, 6631 .

(38) Mason, B. J.; King, S.-J.; Miles, R. E. H.; Manfred, K. M.; Rickards, A. M. J.; Kim, J.; Reid, J. P.; Orr-Ewing, A. J. Comparison of the Accuracy of Aerosol Refractive Index Measurements from Single Particle and Ensemble Techniques. J. Phys. Chem. A 2012, $116,8547-8556$.

(39) Lu, J. W.; Isenor, M.; Chasovskikh, E.; Stapfer, D.; Signorell, R. Low-temperature Bessel Beam Trap for Single Submicrometer Aerosol Particle Studies. Review of Scientific Instruments 2014, 85, 095107.

(40) Lu, J. W.; Rickards, A. M. J.; Walker, J. S.; Knox, K. J.; Miles, R. E. H.; Reid, J. P.; Signorell, R. Timescales of Water Transport in Viscous Aerosol: Measurements on SubMicron Particles and Dependence on Conditioning History. Phys. Chem. Chem. Phys. 2014, 16, 9819-9830.

(41) Bohren, C. F.; Huffman, D. R. Absorption and Scattering of Light by Small Particles; Wiley-Blackwell, 1998.

(42) Richardson, C. B.; Hightower, R. L.; Pigg, A. L. Optical Measurement of the Evaporation of Sulfuric Acid Droplets. Appl. Opt. 1986, 25, 1226-1229. 